\title{
Subramanian hyphomycetes: a tribute
}

\author{
Roland Kirschner $^{1}$ P Pedro W. Crous ${ }^{2}$
}

Published online: 8 November 2016

(C) German Mycological Society and Springer-Verlag Berlin Heidelberg 2016

The present issue of Mycological Progress is dedicated to the memory of Chirayanthumadom Venkatachalier Subramanian (1924-2016), "CV", who passed away on the 4th of February 2016 at the age of 92. A memoir of his life appeared in the journal he founded, Kavaka, the very week before his death, and this manuscript should be consulted to gain more insight into the mycological career of CV Subramanian (http://fungiindia.co. in/images/kavaka/45/45.pdf) (Subramanian 2016).

Early in his career, CV was fascinated by the taxonomy and pathology of the genus Fusarium, and when he finally got the opportunity to visit the Commonwealth Mycological Institute in England, E.W. Mason informed him that there was no staff member to help him with Fusarium, but that he may look at hyphomycetes instead, which started his long journey with tropical mycology. In Europe CV got the opportunity to meet many of the mycological greats, who were experts on important genera of hyphomycetes at the time. Upon his return to Madras in India, he feverishly started collecting hyphomycetes. One of the genera he introduced as Beltraniella (see paper by Rajeshkumar et al. in this issue). He wrote in his memoir that he remembered collecting it on a morning when the dew drops were still present on the fallen leaves, and thus assumed that it was an initial colonizer of litter, rather than a

Section Editor: Pedro W. Crous and Roland Kirschner

Pedro W. Crous

p.crous@cbs.knaw.nl

Roland Kirschner

kirschner@ncu.edu.tw

1 Department of Life Sciences, National Central University, Taoyuan City, Taiwan

2 CBS-KNAW Fungal Biodiversity Centre, Uppsalalaan 8, 3584 CT Utrecht, The Netherlands soil fungus. Further research was later to show that the Beltraniaceae were rather common fungi in India, and no doubt many await to still be collected. In fact, these fungi were found to be present from Asia to Europe to Africa and Cuba, and it puzzled CV how speciation occurred in a genus with such a wide geographical distribution! His recollection of the letters shared between him and F. Petrak (the then editor of Sydowia), is enough to make any mycologist smile. CV travelled widely, and even managed to participate in the famous Kananaskis meetings (The Whole Fungus) in Canada, organized by W.B. Kendrick. The excitement of linking "anamorphs" to "teleomorphs" and understanding conidiogenesis, was the flavour of the day.

CV also played an important part in the First International Mycological Congress in Exeter, England in 1971, by setting up a mycological committee to represent India. He was also subsequently elected as president on the IMA (1977-1983) (Simmons 2010). In 1973 he launched the Mycological Society of India, and established its own journal, Kavaka. In spite of his many accomplishments, achievements and awards, CV is probably best known internationally for his work on hyphomycetous fungi, which resulted in a major monograph of the Indian species (Subramanian 1971). In accordance with this monumentous publication, the present issue of Mycological Progress thus also focuses on hyphomycetous fungi, integrated into the new one fungus = one name classification. The issue contains 13 contributions, covering genera such as Aspergillus, Beltraniella, Bipolaris, Botrytis, chaetothyrialean fungi, Clonostachys, Lecophagus, Pseudocercospora, Sporidesmioides, Sporoschisma, Talaromyces, and verticillium-like fungi. We hope that this compilation would be a fitting contribution to the proud legacy of a great mycologist and larger than life personality.

Some jewels hidden in the Subramanian's memoirs are reprinted below: 
"A unique flora must harbour unique fungi."

"Collecting fungi is an art."

"The more carefully one looked for fungi in a single location and on different kinds of leaves and twigs, and these in different states of decomposition, the greater the chance of new discoveries."

"Why are some fungi not readily found, unlike others that turn up on continents far apart?"

"Why are some genera monotypic?"

"As in life, so in science, we should not lose our ethical sense."

\section{References}

Simmons EG (2010) The International Mycological Association: its history in brief with summaries of its international mycological congresses and diverse international relationships. IMA Fungus 1:18 100

Subramanian CV (1971) Hyphomycetes: an account of Indian species, except Cercosporae. Indian Council of Agricultural Research, New Dehli

Subramanian CV (2016) ["2015"] The pursuit of mycology in the tropics: recollections. Kavaka 45:1-102 